\title{
褐藻類アカモク・ヤッマタモクの幼肧执よび葉状部の 成長に及ぼす光質・光量の影響*1,2
}

\author{
松井敏夫, 大貝政治, 村瀨 昇
}

(1994 年 3 月 31 日受付)

The Effects of Light Quality and Quantity on Germling and Thallus Growth in Sargassum horneri and S. patens

Toshio Matsui, ${ }^{* 3}$ Masaharu Ohgai, ${ }^{* 3}$ and Noboru Murase ${ }^{* 3}$

\begin{abstract}
The effects of light quality and quantity on growth of germlings and thalli of Sargassum horneri and $S$. patens were examined in an indoor culture. Red, green, blue and white light were used at 3-5 different levels from 10 to $120 \mu \mathrm{E} / \mathrm{m}^{2} / \mathrm{s}$. The effect of light quality on their growth was the same in the germlings and thalli of both species. Growth of $S$. horneri was the best under white and blue light, better under green, but very poor under red light. Though $S$. patens did not grow under red light, it grew vigorously at similar rates under the other three light sources. As for the light quantity, both species grew well with more light. S. horneri grew 2-4 times faster than $S$. patens.
\end{abstract}

キーワード: アカモク, ヤッマタモク, 幼胚, 成葉, 光質, 光量, 成長

海藻の生育と光との関係について，著者らは先にコン フ十目数種の配偶体の成長・成熟および胞子体 (幼葉) の 成長に及ぼす光賈・光䡒の影響を報告した。方，木 ンダワラ類については, 幼肧の発生様式や形態形成につ

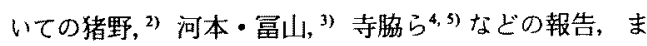
た，奻胚の成長と光の関係についての小河, ${ }^{* 4}$ Hales and Fletcher ${ }^{6}$ の研究があるが, 幼肧, 葉状部の成長と光質・ 光量の関係について明らかにした報告はこれまでほとん ぼみら机い。そこで, 本研究ではアカモク,ヤッマタ モクの奻胚および葉状部の成長上光質・光量の関係を検 討したので，その結果を報告する。

\section{材料および方法}

材料 アカモク Sargassum horneri の幼肧は母藻採集 時に生殖器休に付着していたものを集めて実験材料とし たが, ヤッマタモクS patensでは採取した成熟母藻を流 海水中で空内培養し，1〜3日後に放出された卵をキャピ ラリーで採取した。このようにして得られた卵や纤胚を 隇菌海水でよく洗浄し，培養液を入れて底に $18 \times 18 \mathrm{~mm}$ のカバーガラスを敷いたシャーレ中に散布した。これを
2〜3 日間静置して幼胚をカバーガラスに着生させ，奏験 に使用しだ。1枚のカバーガラスに着生した幼肧数はア カモクでは平均約 45 個体, ヤッマタモクでは平均約 83 個体であった。なお，開始時の奻肧は多くの場合，仮根 がわずかに伸びている発生初期段階のものであった。ま た，実験の開始時期はアカモクが 4 月下旬（水温約 $14.8^{\circ} \mathrm{C}$ ), ヤッマタモクが 6 月上旬 (水温約 $18.8^{\circ} \mathrm{C}$ ) で あった。葉状部については，末熟個体の茥（アカモク）や 主枝（ヤッマタモク）を，先端から長さ $2 \mathrm{~cm} に$ に切断し， 雑藻を除去して材料とした。実験開始時の葉状部の湿重 量はアカモクでは 92.3〜 168.3 $\mathrm{mg}$, 平均 $123.8 \mathrm{mg}$, ヤッ マタモクでは 80.5 150.3 $\mathrm{mg}$, 平均 $113.2 \mathrm{mg}$ であった。 これらの実験はアカモクで 1 3月,ヤッマタモクで3 月に実施した。なお，これらの母藻や材料は山口県豊浦 郡豊浦町沿岸の浅所で採取した。

培菟方法 幼胚については，小形シャーレ（内径 45 $\mathrm{mm}$, 高さ $15 \mathrm{~mm}$ ）に幼胚着生の力バーグラスをアカモ クでは 4 枚，ヤッマタモクでは 3 枚ずつ入れ，前報りの コンブ目配偶体の場合上同様な方法で静置培養した。ま た，葉状部については容量 $500 \mathrm{ml}$ の平底フラスコにア

*: 海藻の光特性に関する研究一II (Studies on Seaweeds' Relation to Properties of Light-11)

*2 本研究は，科学技術厅の昭和 $61 \sim 63$ 年度の科学技術掁興調整賴に上る「海洋深層資源の有効利用技術の開発に関する研究」の中 の「光利用による海中緑化技術に関する研究」の一環として実施された.

*3 水産大学校增殖学科 (Shimonoseki University of Fisheries, Nagatahonmachi, Shimonoseki, Yamaguchi 759-65, Japan).

* 小河久朗: ホンシダワラ類の奻胚の発生に及ぼす温度, 光, 塩分濃度の影響について, 昭和 55 年度文部省科学研究費補助金（総合 研究 A) 研究成果報告畫, 藻場 (ガラモ場) の生態の総合研究, 1981, pp. 51-54. 


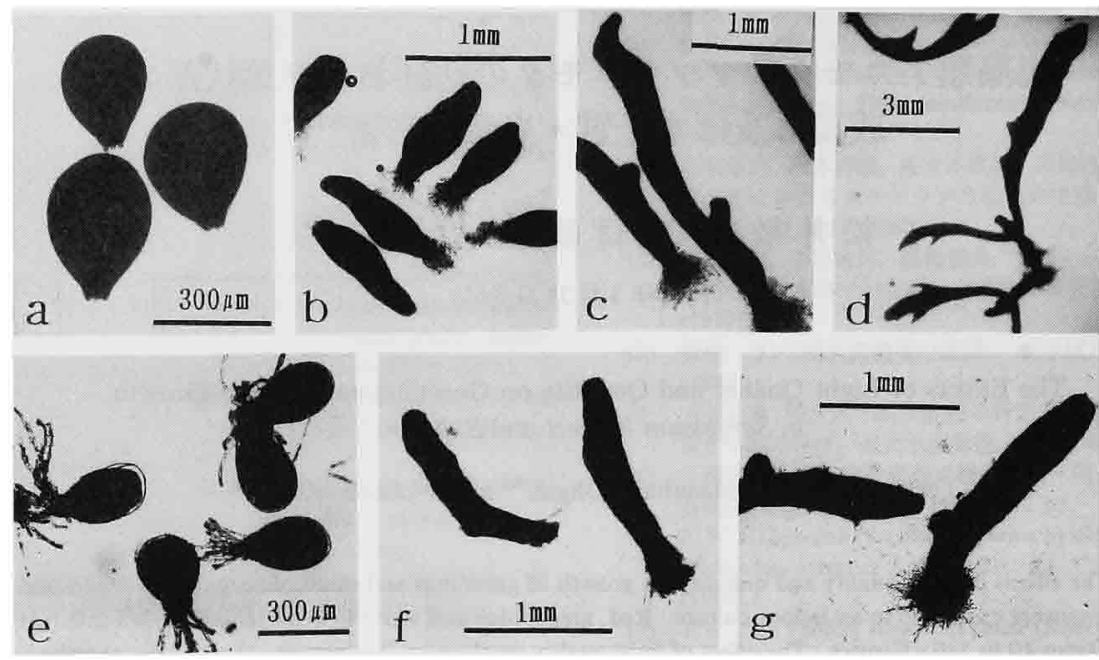

Fig. 1. Development of the germlings of Sargassum horneri (a-d) and $S$. patens (e-g).

a, e, the germlins when culture starts; $b$, after 5 days; $c$, after 10 days; $d$, after 20 days; $f$, after 15 days; $\mathrm{g}$, after 20 days.

Table 1. Length of first primary leaf and percentage of germlings with various branching of primary leaf after 20 days culture in different quantum irradiances of red, green, blue, and white fluorescent light at $14-16^{\circ} \mathrm{C}$, in Sargassum horneri

\begin{tabular}{|c|c|c|c|c|c|c|c|}
\hline \multirow{2}{*}{ Light quality } & \multirow{2}{*}{$\begin{array}{l}\text { Quantum } \\
\text { irradiance } \\
\left(\mu \mathrm{E} / \mathrm{m}^{2} / \mathrm{s}\right)\end{array}$} & \multirow{2}{*}{$\begin{array}{l}\text { Length of first } \\
\text { primary leaf*1 } \\
\qquad(\mu \mathrm{m})\end{array}$} & \multicolumn{5}{|c|}{ Number of primary leaf } \\
\hline & & & 1 & 2 & 3 & 4 & 5 \\
\hline \multirow[t]{5}{*}{ Red } & 10 & $372 \pm 27 * 2$ & 100 & 0 & 0 & 0 & 0 \\
\hline & 25 & $492 \pm 134$ & 100 & 0 & 0 & 0 & 0 \\
\hline & 50 & $712 \pm 364$ & 100 & 0 & 0 & 0 & 0 \\
\hline & 75 & $766 \pm 284$ & 100 & 0 & 0 & 0 & 0 \\
\hline & 100 & $1,159 \pm 427$ & 100 & 0 & 0 & 0 & 0 \\
\hline \multirow[t]{5}{*}{ Green } & 10 & $570 \pm 114$ & 100 & 0 & 0 & 0 & 0 \\
\hline & 25 & $1,219 \pm 323$ & 100 & 0 & 0 & 0 & 0 \\
\hline & 50 & $1,823 \pm 515$ & 95 & 5 & 0 & 0 & 0 \\
\hline & 75 & $2,727 \pm 591$ & 23 & 77 & 0 & 0 & 0 \\
\hline & 100 & $4,020 \pm 613$ & 0 & 30 & 55 & 15 & 0 \\
\hline \multirow[t]{5}{*}{ Blue } & 10 & $1,949 \pm 603$ & 86 & 14 & 0 & 0 & 0 \\
\hline & 25 & $3,313 \pm 898$ & 30 & 55 & 15 & 5 & 0 \\
\hline & 50 & $4,616 \pm 791$ & 5 & 50 & 30 & 15 & 0 \\
\hline & 75 & $4,400 \pm 1,415$ & 10 & 15 & 55 & 20 & 0 \\
\hline & 100 & $3,461 \pm 607$ & 0 & 5 & 25 & 50 & 20 \\
\hline \multirow[t]{5}{*}{ White } & 10 & $1,801 \pm 411$ & 100 & 0 & 0 & 0 & 0 \\
\hline & 25 & $2,773 \pm 566$ & 50 & 50 & 0 & 0 & 0 \\
\hline & 50 & $4,710 \pm 1,242$ & 5 & 85 & 10 & 0 & 0 \\
\hline & 75 & $3,819 \pm 1,265$ & 15 & 85 & 0 & 0 & 0 \\
\hline & 100 & $4,667 \pm 1,180$ & 11 & 71 & 18 & 0 & 0 \\
\hline
\end{tabular}

*I Initial length of germling was $356 \pm 37 \mu \mathrm{m}$.

*2 Mean \pm S.D. of 20 specimens. 
カそクで4個体，ヤッマタモクで3個体ずつ入れて通気 しながら培養した。各実験の期間は15２0日間，温度は

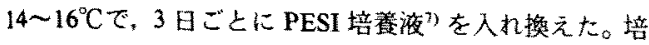
湌期間中には奻肧や葉体に珪藻な゙よ゙が付著して增殖する 場合がみられたので，その際には培養液交換期に筆やピ ンセットを使用してできるだけをれらを取り除いて実験 を続行させた。光条件は, 前報”之同様に, 紅色, 緑色, 青色，白色の $20 \mathrm{~W}$ 三菱紗光ランプを光源として東芝 シャープカットフィルター $(5 \mathrm{~cm}$ 平方 $)$ を併用し, 幼胚 については上方から，葉状部については下方加をを机ぞ れ照射した。また，各光䁚ごとに3〜5段階の光量区を設 けて1日12時間明期とした。なお，葉状部代つけては $500 \mathrm{ml}$ フラスコが収容できる1辺約 $10 \mathrm{~cm}$ の低のない 紙箱を作り，その底にシャープカットフィル夕ーを4数 並べて (10 cm 平方)，その上に培養つラスコを置いて培 裳した。

成長度の測定 幼胚については，培養5 日以後の所定 日に,アアカモクについては20個体を、ヤッマタモクでは 30 個体をそれぞれの力バーがラスから外して，仮根を除 く発芽体の長さ老測定し，\{(測定日の平均葉長一開始日 の平均葉長) $\times 100 /$ 開始日の平均葉長 で成長度表し た。なお、発芽体が分岥した場合にはそれぞれの葉の長 さを合わせたものを葉長しした。葉状部につけては澌定 直前に源紙で水滴を拭い上った後, 生重晋を测定し，ア カモクは4個体，ヤッマ夕モクは3 個体について，\{(测 定日の平均湿重量一開始日0平均鼬重量) $\times 100 /$ 開始日 の平均湿重量〕で増重率を表した。

\section{結果}

\section{纤胚}

1. アカモク 各光質に $10,25,50,75,100 \mu \mathrm{E} / \mathrm{m}^{2} / \mathrm{s}$ の 5 光量区を設け，5，10，15，および20日後に各区20值体 について葉長を測定した。なお，培養開始時の発芽体の

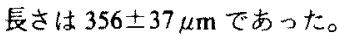

幼左は成長すると，先ずやや雇圧した円柱状の第 1 葉 を形成し， と分岐して葉数加增え，第2，第3 葉には縁辺に浅い可 れ込みが㒛められるようになった (Fig. 1a-d)。分岥が最 も早期にみられたのは青色光の $100 \mu \mathrm{E} / \mathrm{m}^{2} / \mathrm{s}$ 区で，培恤 5 日後の数個体に長さ $0.3 \mathrm{~mm} の$ 第 2 葉がみられた。ま た，白色光と緑色光では培養 10 日後の壱光晊区で分岐 した発芽体が多く観察されだ。培求20日後における第 1 初期葉の葉長ならびに葉数を Table 1 に示す。葉長は青 色光，由色礼で長く，ついで緑色光で，紅色光では短 かった。葉数は紅色光を除いて各光質とも高光量ほど多 くなる傾问にあった。光質別にみると青色光で最委多 く,っいで白色光，緑色光であった。しかし紅色光では

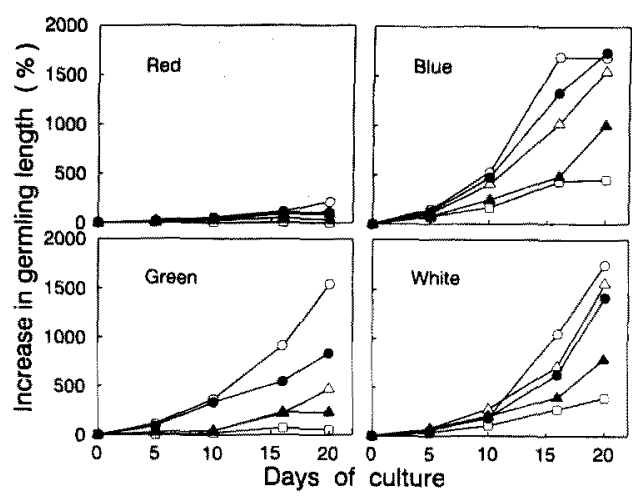

Fig. 2. Growth of Sargassum horneri germlings (excluding rhizoids) in culture at different quantum irradiances of red, green, blue, and white fluorescent light at $14-16^{\circ} \mathrm{C}$.

Light quantities: $\bigcirc, 100 ; \bullet, 75 ; \triangle, 50 ; \boldsymbol{\Delta}, 25$; $\square, 10 \mu \mathrm{E} / \mathrm{m}^{2} / \mathrm{s}$.

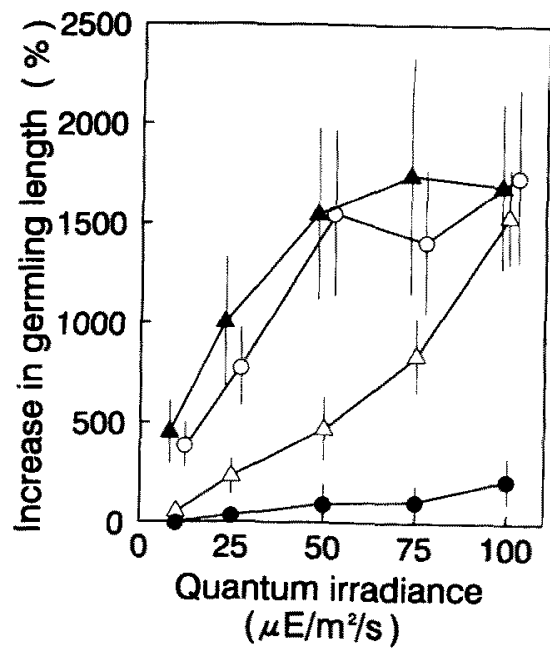

Fig. 3. Growth of Sargassum horneri germlings (excluding rhizoids) after 20 days culture in different quantum irradiances of red $(\boldsymbol{O})$, green $(\triangle)$, blue $(\Delta)$, and white $(O)$ fluorescent light at $14-16^{\circ} \mathrm{C}$.

Vertical bars indicate standard deviations $(n=20)$.

各光量区ともすべて第1葉のままであった。

培美中心成長度を Fig. 2 に示す。紅色光を除く各光質 の㭃肧流いずれも培養日数の経過に伴ってしだいに伸長 し，また高光量ほどょく成長した。培養 10 ならびに 15 日後における光暂別成長度は青色光で鼠㐘よく，ついて 白色光，緑色光であり，紅色光では非常に劣っていた。 しかし培養 20 日徭における成辰度と光量の関係はFig 3 で示したように，白色光でも青色光と同程度の成長が 
Table 2. Length of first primary leaf and percentage of germlings with various branching of primary leaf after 20 days culture in different quantum irradiances of red, green, blue, and white fluorescent light at $14-16^{\circ} \mathrm{C}$, in Sargassum patens

\begin{tabular}{|c|c|c|c|c|c|}
\hline \multirow{2}{*}{ Light quality } & \multirow{2}{*}{$\begin{array}{l}\text { Quantum } \\
\text { irradiance } \\
\left(\mu \mathrm{E} / \mathrm{m}^{2} / \mathrm{s}\right)\end{array}$} & \multirow{2}{*}{$\begin{array}{l}\text { Length of first } \\
\text { primary lea }{ }^{* 1} \\
(\mu \mathrm{m})\end{array}$} & \multicolumn{3}{|c|}{ Number of primary leaf } \\
\hline & & & 1 & 2 & 3 \\
\hline \multirow[t]{4}{*}{ Red } & $\begin{array}{l}10 \\
25\end{array}$ & $\begin{array}{l}386 \pm 61^{* 2} \\
600 \pm 144\end{array}$ & $\begin{array}{l}100 \\
100\end{array}$ & $\begin{array}{l}0 \\
0\end{array}$ & $\begin{array}{l}0 \\
0\end{array}$ \\
\hline & 50 & $585 \pm 107$ & 100 & 0 & 0 \\
\hline & 75 & $587 \pm 112$ & 100 & 0 & 0 \\
\hline & 100 & $588 \pm 133$ & 100 & 0 & 0 \\
\hline \multirow[t]{5}{*}{ Green } & 10 & $484 \pm 88$ & 100 & 0 & 0 \\
\hline & 25 & $913 \pm 135$ & 100 & 0 & 0 \\
\hline & 50 & $1,107 \pm 195$ & 100 & 0 & 0 \\
\hline & 75 & $1,533 \pm 360$ & 100 & 0 & 0 \\
\hline & 100 & $1,656 \pm 375$ & 100 & 0 & 0 \\
\hline \multirow[t]{5}{*}{ Blue } & 10 & $721 \pm 147$ & 100 & 0 & 0 \\
\hline & 25 & $908 \pm 182$ & 97 & 3 & 0 \\
\hline & 50 & $1,010 \pm 249$ & 100 & 0 & 0 \\
\hline & 75 & $1,283 \pm 199$ & 93 & 7 & 0 \\
\hline & 100 & $1,437 \pm 220$ & 83 & 13 & 3 \\
\hline \multirow[t]{5}{*}{ White } & 10 & $466 \pm 84$ & 100 & 0 & 0 \\
\hline & 25 & $816 \pm 172$ & 100 & 0 & 0 \\
\hline & 50 & $1,146 \pm 275$ & 100 & 0 & 0 \\
\hline & 75 & $1,292 \pm 157$ & 97 & 3 & 0 \\
\hline & 100 & $1,300 \pm 246$ & 80 & 20 & 0 \\
\hline
\end{tabular}

*: Initial length of germling was $236 \pm 24 \mu \mathrm{m}$.

*2 Mean \pm S.D. of 30 specimens.

みられた。光量増加に伴う成長は，青色光と白色光では $50 \mu \mathrm{E} / \mathrm{m}^{2} / \mathrm{s}$ をで光量とほぼ正比例の関係にあったが，そ れ以上の光量では大きな成長增加がみられなかった。こ れに対して粶色光での成長は，低光量では劣っている が，光量が $50 \mu \mathrm{E} / \mathrm{m}^{2} / \mathrm{s}$ をこえてい成長增加がみられ， $100 \mu \mathrm{E} / \mathrm{m}^{2} / \mathrm{s}$ では青色光や白色光とほぼ同程度を示し た。しかし紅色光では高光噩下であ成長が不良であっ た。

培養開始時に平均約 $360 \mu \mathrm{m}$ あった幼胚の葉長は, 20

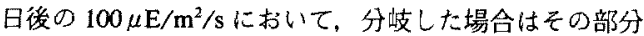
の長さむ加えて青色光で平均 $6.4 \mathrm{~mm}$, 白色光で 6.6 $\mathrm{mm}$, 緑色光で $5.9 \mathrm{~mm}$, 紅色光で $1.1 \mathrm{~mm}$ であった。

2. ヤッマタモク 契験はアカモクについて上同じ5 光量区を設けて 20 日間行い，その5 日ごとに各区 30 個 の発芽体について長さを測定した。なお，開始時の材料 の平均葉長は $236 \pm 24 \mu \mathrm{m}$ であった。

発芽体の初期形態は Fig. $1 \mathrm{e}-\mathrm{g}$ のおりで, 発生が進 むとやや扁仕した円将状の第 1 初期葉" $の$ 中央付近から 第 2 初期葉が形成され始めた。第 1 初期葉の葉長および 葉数の変化については Table 2 に示すように，葉長は緑 色光が最も長く, ついで青色光，白色光，紅色光の順で，

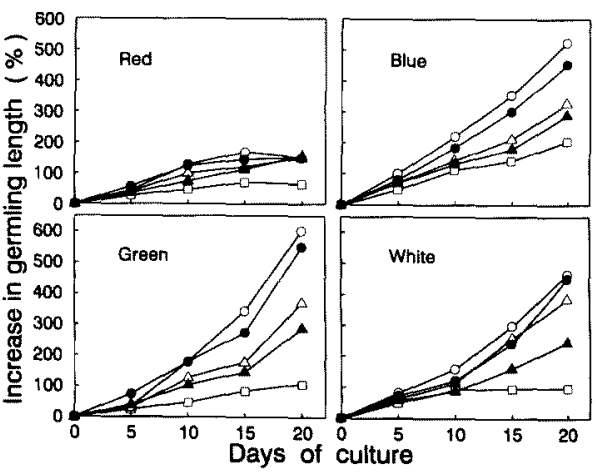

Fig. 4. Growth of Sargassum patens germlings (excluding rhizoids) in culture at different quantum irradiances of red, green, blue, and white fluorescent light at $14-16^{\circ} \mathrm{C}$.

See Fig. 2 for further explanation.

光量の増加に伴って長くなっだ。しかし葉数の変化をみ ると紅色光と緑色光では各光量区之も実験 20 日後まで 第 1 葉のみであったが, 青色光之白色光では $75 \mu \mathrm{E} / \mathrm{m}^{2} / \mathrm{s}$ 以上の奏験区において一部の個体に第 2 葉の形成が認め られた。特に青色光の $100 \mu \mathrm{E} / \mathrm{m}^{2} / \mathrm{s}$ 区では 15 日後に第2 
营，20日後に第3葉が出ている個体がそれぞれ観祭され t。

実験中における成長状況は Fig. 4 のとおりで，各実験 区之它培養日数の経過に伴ってそれぞれの光条件に応し たほぼ一定速度の成長を示した。北量別では高光量ほど よく伸長し，光質別では紅色光を除く 3 光質でほぼ同程 度の順娚な成長がみられた。培盖20日後における光量 と成長度の関係を Fig. 5 に示した。緑色光，青色光お

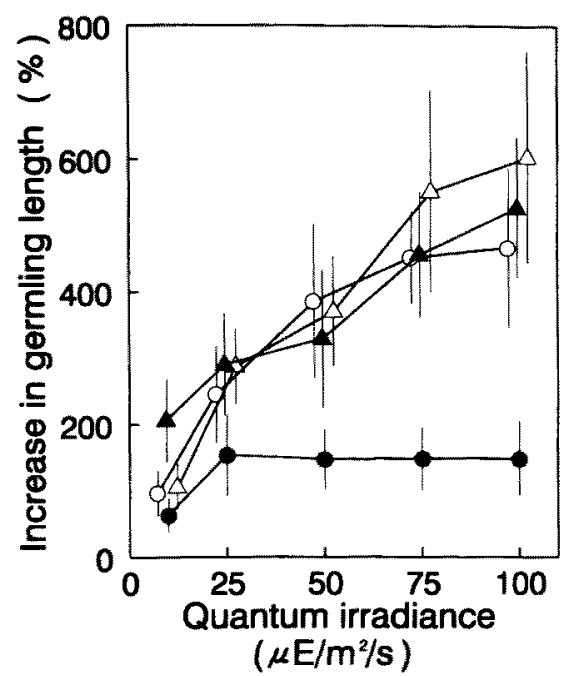

Fig. 5. Growth of Sargassum patens germlings (excluding rhizoids) after 20 days culture in different quantum irradiances of red $(\Theta)$, green $(\triangle)$, blue $(\Lambda)$, and white $(O)$ fluorescent light at $14-16^{\circ} \mathrm{C}$.

Vertical bars indicate standard deviations $(n=30)$.

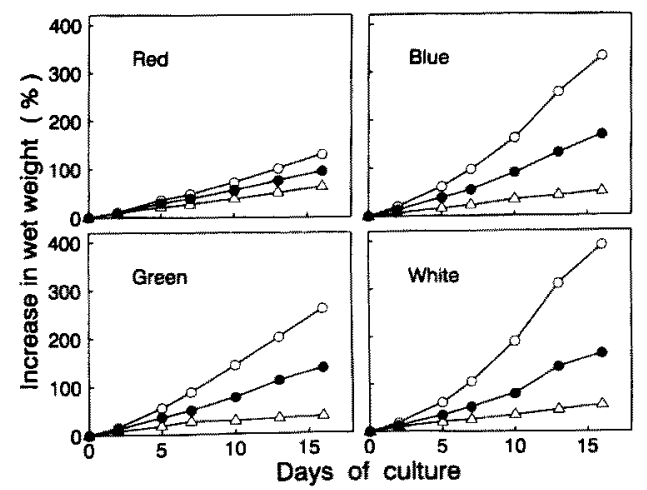

Fig. 6. Vegetative growth of detached thallus tips ( $2 \mathrm{~cm}$ initial length) of Sargassum horneri in culture at different irradiances.

Light quantities: $O, 100 ; 0,50 ; \triangle, 20 \mu \mathrm{E} /$ $\mathrm{m}^{2} / \mathrm{s}$.
よびも色光では，実験した光䁷範囲内 $\left(100 \mu \mathrm{E} / \mathrm{m}^{2} / \mathrm{s}\right.$ 以 下)では，いずれ光光加高いはじよく成長し，光質に よる違いはほとんよ゙なかった。しかし紅色光での成長は 非常に熏く, $25 \mu \mathrm{E} / \mathrm{m}^{2} / \mathrm{s}$ 以上の光量区では成長促進がほ とんどみられかった。

培翻開始時に平均約 $240 \mu \mathrm{m}$ であった幼肧の葉長は， 20 日後の $100 \mu \mathrm{E} / \mathrm{m}^{2} / \mathrm{s}$ において, 分畦した場合はその部 分の長さも加えて青色光で平均 $1.5 \mathrm{~mm}$, 白色光で 1.4 $\mathrm{mm}$, 緑色光で $1.7 \mathrm{~mm}$, 紅色光で $0.6 \mathrm{~mm}$ であっだ。

\section{葉汱部}

1.アカモク 各光㩖ごとに $20,50,100 \mu \mathrm{E} / \mathrm{m}^{2} / \mathrm{s} の 3$ 光量区を設け，各区に4個体ずつの材料を用いて 16 日 間培養し，その間 2,3日ことに成長状泥を調へた。葉体 は培数日経過に伴って葉数が増加し，長さが伸びて きた。重量变化からみた成長状況は Fig. 6 のとおりであ る。低光量下では各光質ともあまり成厔がみられなかっ たが，100 $\mu \mathrm{E} / \mathrm{m}^{2} / \mathrm{s}$ になると光質による違いが明暸に なってきた。すなわち，成長は白色光で最むよく，つい で青色光，緑色光の順であり，紅色光で发っていた。培 盖 16 日後の $100 \mu \mathrm{E} / \mathrm{m}^{2} / \mathrm{s}$ における 4 個体の平均湿重量 は実験開始時の 119.6 から $629.2 \mathrm{mg}$ に, 123.1 から 512.7 $\mathrm{mg}$ に, 116.3 加ら $415.0 \mathrm{mg}$ に, 125.5 加ら $301.5 \mathrm{mg}$ にそ れぞれ増加し，増重率はそれぞれ 430,320,260，および 140\%であっだ。また， $50 \mu \mathrm{E} / \mathrm{m}^{2} / \mathrm{s}$ における增重率は， 尼色光と青色䒕で $165 \%$ とは等しく，緑色光で $140 \%$, 紅色光で 95\%であった。アカモクについては20

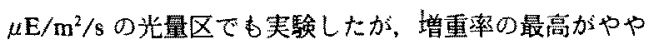
低くて50\%であったはかは，光質之成長との関係は全 く同じであった。

2. ヤッマ夕モク光量段階として $20,60,120$ $\mu \mathrm{E} / \mathrm{m}^{2} / \mathrm{s}$ の 区を設け，各区に材料を 3 個体ずっ入れて

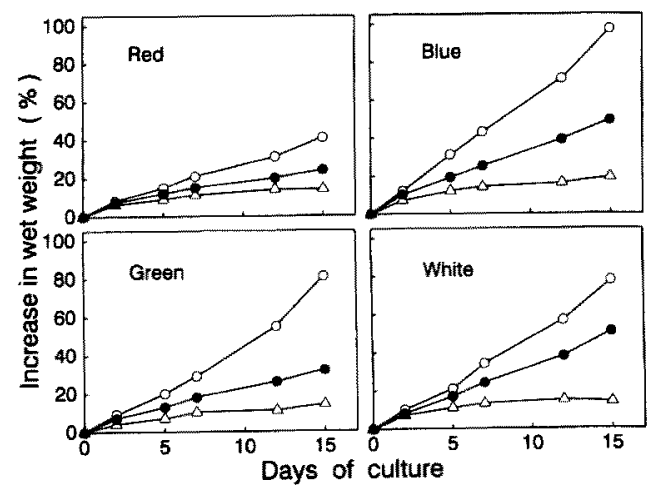

Fig. 7. Vegetative growth of detached thallus tips ( $2 \mathrm{~cm}$ initial length) of Sargassum patens in culture at different irradiances.

Light quantities: 0,$120 ; 0,60 ; \triangle, 20 \mu \mathrm{E} /$ $\mathrm{m}^{2} / \mathrm{s}$. 
15日間培咅した。培養中の成長は Fig. 7 のちおで，各 光質とも光が強くなるにつれて成長も活発になった。ま た光質別では紅色光で少っているほかは，いずれ当はぼ 同程度の成長がみられた。培養 15 日後の $120 \mu \mathrm{E} / \mathrm{m}^{2} / \mathrm{s}$ におけるそれぞれの3 個体の平均湿重量は，青色光では 夷験開始時の 105.2 から $202.0 \mathrm{mg}$ に, 白色光では 116.1 から $208.9 \mathrm{mg}$ に，緑色光では123.7から $227.1 \mathrm{mg}$ に，紅 色光では 103.8 加ら $149.7 \mathrm{mg}$ に增加し，增重率はそれぞ れ 93,80,84,44\%で, 紅色光での成長が特に悪かった。 また， $60 \mu \mathrm{E} / \mathrm{m}^{2} / \mathrm{s} に$ おける增重率は青色光と白色光で 50\%とほぼ等しかったが, 緑色光でやや低く $32 \%$, 紅色 光で $24 \%$ であった。

\section{考察}

アカモク幼胚の成長は発生初期では，青色光区で最も よく，ついで白色光，緑色兆であり，紅色光下では出っ ているが，発生が進むと白色光で青色光之闰程度の好 成長を示す。光量については，青色光と白色光では 50 $\mu \mathrm{E} / \mathrm{m}^{2} / \mathrm{s}$ 以上で活発であり，緑色光では低光置で成長は 良くないが, 光量が増すにつれて青色光とほぼ等しい成 長がみられるが，紅色光では高光量下でも成長が不良で ある。また，発芽体の分岐状況加らても，葉長の長い 成長の活発な青色光が最も多く, ついで白色光・緑色光 であり，紅色光のもとでは分貱しない。ヤッマタモク幼 胚の成長は，発芽体の葉長加みるとアカモクと同様に 紅色光を除く 3 光質で各光量ともはぼ同程度の良好な成 長がみられ，分岐は青色光と白色光で優れていた。光形 態形成については大型藻類での報告はないが; 被子植物 でのキク科植物の切り木の根の発達と光質の関係量をみ ると，根の数や長さは白色光や縕色光下のものが青色光 や緑色光下のものより勝っていたが, 最初に根が出現す るものは逆に緑色光下で最も早かったと報告している。 このように，植物の形態形成は光質によって大きく左右 されることが諗められている。したがって、今回の結果 からアカモクやャッマタモクの葉状部の分吱が青色光で 多かったことは、形態形成が藻類においても光望によっ て大きく影響を受けていると考えられる。これらのこと を含めて今回の結果を総括すると，両種の幼胚は形態形 成が光質によって異なるものの, 白色光，青色光，緑色 光の 75 $100 \mu \mathrm{E} / \mathrm{m}^{2} / \mathrm{s}$ で活発に成長するものと思われ る。沿岸域での光条件は，下田湾での海中光の测定結 果”加ら考えると，水深 $5 \mathrm{~m}$ 付近ではすでに紅色光がほ とんど無くなり，緑绝光や清色光が大部分老占めて，そ
の波長域の光量を計算すると約 $62 \mu \mathrm{E} / \mathrm{m}^{2} / \mathrm{s}$ であった。 アカモクやヤッマタモクの垂直分布をみると一般に水深 $5 \mathrm{~m}$ 以浅に多く成育していたことから，このような海域 での分布はそれぞれの幼还の成長に好適な光条件が存在 していることと関䋆か深いと考えられる。

葉状部は成長点を含む主茎または主伎の先端部を使用 すれば室内培養でも活発に成長することが認められた。 アカモクは白色光での成長が最すよく, ついで青色光, 緑色光の順であって，紅色光では奻还と同様に最も劣っ ている。ヤッマタモクでは縕色光での成長は墨いが，青 色光, 緑色光, 白色光ではいずれもほぼ同椂に順調な成 長を示す。また雨㮔と屯 $100 \sim 120 \mu \mathrm{E} / \mathrm{m}^{2} / \mathrm{s}$ までは光が 强いほど成長む活発である。なお，本実験ではシャープ カットフィルターを通した光で培意を行った結果,この ような光質による成長の違いが認められたが，各色蛍光 ランプの光をのまま使用した実験では, 紅色光下で も他光質之ほは同程度の成長がみられている。これは， シャープカットフィルターを使用しないと, 紅色蛍光ラ ンプから同時に放射される少量の青色光がカットされな いので，その影響によって成長が促進されるからである j。

アカモクとヤッマタモクの各条件下での成長速度を比 較すると，幼㗏之葉状部の成長速度は紅色光下を除け ば、いずれもアカモクの方が 2 4 倍速い。アカモクの幼 还および葉状部がヤッマタモクのそれらより速く成長す ることは吉田・西川新毛報告しているが, 本研究での培 養水温 $\left(15^{\circ} \mathrm{C}\right)$ がアカモクの成長により適している゙ここ とやアカモクの方が大形に成長する゙ことなども，成長 の速さに関係があるものと考えられる。

ホンダワラ類の奻胚の成長と光の関係については比較 的浅所に生筲する夕マハキキク Sargassum muticum を 白色蛍光灯下で 4 週間培養した報告のがある。これによ れば，成長に好筒な光量は $44 \sim 88 \mu \mathrm{E} / \mathrm{m}^{2} / \mathrm{s}$ とされてい るが,この㬰験では1日16時間照射となっているので， 日間皘算光量に換算すると，2.5 $5.1 \mathrm{E} / \mathrm{m}^{2} /$ day となる。 本研究では 1 日 12 時間照射で行っており, 成長が良好 であった光量 75〜 $100 \mu \mathrm{E} / \mathrm{m}^{2} / \mathrm{s}$ 它日間積算光量に換算す ると $3.2 \sim 4.3 \mathrm{E} / \mathrm{m}^{2} / \mathrm{day}$ となり, 光量のみからみると本 咞究の結果上ほぼ同样である。

アカモクおよびヤッマタモクの成長之光質の関係につ いては，前報)での褐藻類コンブ目のアラメ，クロメ， カジメなどの胞子体の成長が青色光で最もよく, 紅色光 では劣るという結果ともほぼ同じである。また，Luning

*3 松井敏夫，大貝政治：海藻の光特性に関する研究. 昭和 $61 \sim 63$ 年度科学技術振興調整蛽，海洋深層資源の有効利用技術の開発に 関する研究（第I期）成果報告書、科学技術竹研究開発局，東京，1990，pp，147-158.

*6松井敏夫，大貝政治：ホンダワラ類(ヤッマタモクとアカモク）の生長と水温. 大量濕排水に対する水産環境アセスメント総合

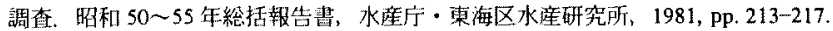


and Neushul ${ }^{12}$ ) はコンブ目 9 種の配偶体の成熟割合が水 温によっても異なるが青色光の総光量に比例すると報告 している。このことから，褐澡類の成長は成熟をも含め て一般に青色光で最すよく,ついで緑色光であり, 紅色 光で劣る傾向があるものと考えられる。また裀藻の光合 成の実験から，影山之横浜 ${ }^{13)}$ は深所産の種が白色光，緑 色光および青色光を同じ効率で利用するのに対して，浅 所産種では緑色光と青色光の利用効率が白色光のそれよ り低いとしている。今回は光合成色素の分析や吸収スべ クトルの測定を行っていないが，幼胚の成長からみる之 今回の 2 種のうち白色光，青色光，緑色光でほぼ等しい 成長を示したャッマタモクの方が緑色光の低光量下で成 長の良くなかったアカモクよりやや樑所産の傾向を示し ている。一方, 葉状部の成長は両種間で光質, 光量に対 する反纫に差はみられず，ヤッマタモクでも低光量下の 緑色光のあとでの成長は，白色光との差が大き加った。 ヤッマタモクでも葉状部の伸長した場合，成長点は水面 近くまで達し，その部分の光環境としては浅所に生育す るものと等しいことと関係するものかむ知れない。海藻 の生育と光質上の関保は，今後之も分布水深の異なる材 料について光合成，葉体の色素分析，成長実験などを追 求していく必要があると思われる。

\section{文献}

1）松井敏夫，大貝政治，大島芳明，古原和明：コンブ目植物 数種の配偶体の成長・成熟㧍よび胞子体 (幼葉) の成長に
及ぼす光質・光量の影響，日水誌，58，1275-1265 (1992)

2）猪野俊平：海藻心発生，第 1 版，北隆館，東京，1947, pp $1-93$.

3) 河本良彦, 富山 昭: ホンダワラ類の增殖に関する研究一

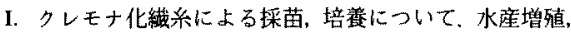
16, 8795 (1968).

4）寺胁利信，野沢洽治，新村 藏：ホンダワラ類の初期形態 髟成に関する研究一II.ヤッマタモク。藻類，31，38-43 (1983).

5）寺勝利信，野沢治治，新村 策：ホンダワラ類の初期形斯 形成に関する咞究一III. 了力モク。藻類，31，97-101 (1983).

6) J. M. Hales and R. L. Fletcher: Studies on the recently introduces brown alga Sargassum muticum (Yendo) Fensholt IV. The effect of temperature, irradiance and salinity on germling growth. Botanica Marina, 32, 167-176 (1989).

7) M. Tatewaki: Formation of a crustaceous sporophyte with unilocular sporangia in Scytosiphon lomentaria. Phycologia, 6, 62-66 (1966)

8) E. Borowski and L. Kozlowska: The Infuence of Light Color on the Rooting of Horim Golden Chrysahthemum cuttings. ACTA Agrobotany, 39, 47-58 (1986).

9）影山明美，横浜康継：深所性緑藻之光合成，藻類，25，167175 (1977).

10）吉田範秋，西川 博：ホンダワラ類の生長. 長䗁県水産試 験場研究報告, 1, 13-18 (1975).

11）瀬川宗吉，沢田武男，桧垣正浩，吉田忠生：流れ藻の海藻 学的研究一IV，流九藻調查資料加ら見たホンダワラ類の 生長. 九大䀼学部学術䧴誌, 17, 429-435 (1960).

12) K. Lüning and $M$. Neushul: Light and Temperature Demands for Growth and Reproduction of Laminarian Gametophtytes in Southern and Central California. Marine Biology, 45, 297-309 (1978).

13）影山明美, 横浜康継：生育深度老異にする褐藻の光合成特 性. 藻類, 22, 119-123 (1974) 